\title{
Perceptions and barriers toward sexual reproductive health services accessibility, availability and quality among adolescents in selected cities of Rwanda
}

Pacifique Ndayishimiye ( $\sim$ pacimiye@gmail.com )

Youth Service Organization (YSO)

Roseline Dzekem Dine

Youth Service Organization (YSO)

Aline Dukuze

Youth Service Organization (YSO)

Isabelle Kubwimana

Youth Service Organization (YSO)

Jean Baptiste Nyandwi

University of Rwanda College of Medicine and Health Sciences Huye

Emmanuel Biracyaza

Youth Service Organization (YSO)

\section{Research}

Keywords: Adolescents, SRHS availability, SRHS accessibility, Second cities, SRHS quality

Posted Date: March 26th, 2020

DOI: https://doi.org/10.21203/rs.3.rs-19213/v1

License: () (1) This work is licensed under a Creative Commons Attribution 4.0 International License. Read Full License 


\section{Abstract}

Background: A fifth of the global population is made up of adolescents. Sexual reproductive health needs for young people is largely ignored by existing health, education and other social programs. In Rwanda, there is still an increase in teen pregnancies, HIV/ STIs as well as reports on the lack of access to accurate SRH information. The study aimed to explore the perceptions and barriers toward sexual reproductive health services accessibility, availability and quality among adolescents in the second cities of Rwanda.

Methods: Cross-sectional study was conducted in six selected cities of Rwanda. In-depth interviews were conducted using semi-structured questionnaires among 121 adolescents aged 10-19 years old living in six selected cities.

Results : Majority of the participants were female $62.8 \%$ and aged between 15-17 years old $32.8 \%$. Females adolescents were more aware, and adolescents with primary school level $62.5 \%$ were not aware about SRH services provision at health facilities. Adolescents were mostly aware about the availability of HIV testing and circumcision services at 102 ( 86.4\%). Results indicate that utilization of SRH services remains low (34.7\%) among adolescents. A recent utilization of a particular service was linked to a use in the past: "I am aware of my HIV status because I was tested when I was going to receive a transfusion at a hospital" (Female participant, Rwamagana). Family, socio-cultural, religious influences and lack of privacy, high costs for the services, unavailability of some services at private facilities as well as lack of comfortable separated rooms, were the barriers reported by adolescents that prevented them from utilising $\mathrm{SRH}$ services.

Conclusion : Accessibility to SRH services for adolescents remains low and SRH services provision doesn't offer confidentiality to adolescents who seek services at health facilities. Family influences, socio-cultural stigma and religious barriers remain a burden to adolescents' SRH services utilization. Increasing community outreach and adolescent's engagement is needed to enable access to accurate SRH information. Multidisciplinary stakeholders should collaborate and cooperate to address the stigma associated with access to SRH services for adolescents.

\section{Plain English Summary}

Sexual Reproductive health problems remain the public health concern worldwide. Although a fifth of the global population is made up of adolescents, the sexual reproductive services for adolescents remain poor in most lowand middle-income countries. Rwanda is of these countries that still face an increase of sexual reproductive health problems such as teen pregnancies and HIV/ STIs. The purpose of this study was to understand the perceptions and barriers toward sexual reproductive health services accessibility, availability and quality among adolescents in the second cities of Rwanda. A study was conducted in six selected cities of Rwanda by interviewing adolescents aged 10-19 years.

The study indicated that utilization of SRH services was low among adolescents, whereby half of sexual reproductive health services that were known to be provided was HIV testing. Awareness of the SRH services availability among adolescents was high. We found low awareness among illiterate boys and adolescents with primary school level. The study found that services were free of charge to public health facilities, but it indicated poor utilisation of sexual reproductive services due to family, socio-cultural, religious influences, lack of information about services, high costs for the services at private facilities, no comfortable separated room adults from adolescents and unavailability of some service.

Page 2/23 
We have concluded that, although availability of SRH services is high, its accessibility is still challenging for adolescents due to lack of awareness on available services at health facilities but also due to barriers such as family influences, uncomfortable rooms for adolescents which are separated to the adults ones.

\section{Background}

Adolescents' health is important to every society as it is one of the tools for economic development, and public health [1]. About one fifth of the global population is made up of adolescents. The overall burden of disease in adolescents is recorded to be at $23 \%$ due to early pregnancies, gender-based violence, HIV/STIs, unsafe abortions, among other causes [2]. Investing in adolescent health could prevent about 1.4 million deaths in adolescents annually [3]. Although the sexual reproductive health (SRH) problems are the global burdens among adolescents, these health issues are more likely to be found in sub-Saharan African countries [4]. Those SRH problems include the unwanted pregnancies, HIV/AIDS infections, unsafe abortion and their consequences, and other STDs [5].

Adolescent sexual and reproductive health had been the major agenda during the1994 International Conference on Population and Development (ICPD). During this meeting, reproductive health needs of young people were discovered to be largely ignored by existing health, education, and other social programs while their health could improve economic prosperity in all sectors of communities [6, 7]. Indeed, Sexual and reproductive health services (SRHS) ought to provide health information, education and counselling, provision of a range of safe and affordable contraceptive methods, quality obstetric and antenatal care for all pregnant girls, testing (pregnancy and HIV), prevention and management of STIs, promotional activities, and encourage active participation of adolescents [7, 8]. The studies conducted in Kenya indicated that the perceptions of adolescents to the SRH services are not uniform, and it is characterized by the variabilities according to gender and the type of SRH service being sought. For instance, the girls seeking antenatal care (ANC) and family planning (FP) services at health facilities characterize the available SRH services, as good and staff, as helpful while boys feel comfortable in seeking any SRH service within the health facilities [4].

It was also found that knowledge on existing SRH services was very poor and boys were totally unaware of adolescents and youth health services available through the public health system. The same researchers documented the lack of availability of SRH services which was an important challenge to reach the adolescents' needs. Among the other barriers found in the previous studies, we found the lack of confidentiality, adolescents and youth friendliness and accessibility of available SRH services [9]. A review of the International Conference on Population and Development (ICPD $\left.{ }^{+} 15\right)$ conducted a study, 10 years after 1994, and revealed that teenage pregnancies remain a major problem, especially in sub-Saharan African countries. The analysis from ICPD +15 , 10 years later showed that 120/1000 of women aged 15-19 years have given birth [10]. Additionally, during the ICPD ${ }^{+} 20$ review, the same problem persisted especially in adolescents aged 10-14 [3].

Other studies state that only $10 \%$ of young men and $15 \%$ of young women were aware of their HIV status by 2014 $[11,12]$. It was recently found that the majority of adolescents still lack awareness and autonomy to access SRH related information and services [13]. HIV testing and counseling had been accessed by less than $30 \%$ within those aged 15-19. In 2015, 79\% of new HIV infections in adolescents were recorded in Sub-Saharan African countries [14]. Most Sub-Saharan Africa countries lack skilled counselors and youth serving professionals to provide SRH Services to adolescents $[11,14]$. Besides this, other studies indicated that the poor accessibility to $\mathrm{SRH}$ services among adolescents were associated with the socio-cultural constraints such as parents who limit 
their adolescents to access SRH services and including parents not providing education related to $\mathrm{SRH}[13,15$, 16]. Having fear and shame among adolescents for using the SRH services was also found as the barrier [17]. Other researchers documented that the financial means, lack of knowledge of service locations, school or community and family pressure, privacy violations, limitations in sexual education for male and females' adolescents, negative interactions with health providers, and pain associated with the SRH services were the barriers to the SRH utilization [18].

Services that are adolescent friendly and function according to the 2014 World Health Organization (WHO) standards, should aim at providing information, education, and health services to help adolescents understand their sexuality and protect them from unintended pregnancy and STIs including HIV/AIDS [12].

The Rwandan Government and stakeholders with respect to Rwanda's Fourth Health Sector Strategic Plans to meet up with SRH needs of adolescents by 2024, invests in youth Corner's and centers wherein services are being provided [19]. Despite efforts, studies still identify that existing Youth Friendly Centers providing SRH services to adolescents in Rwanda which are not to standards. According to WHO standards, a friendly SRHS has to be equitable, accessible, acceptable, appropriate, and effectively provided to adolescents [20]. The unmet needs of adolescents in Rwanda are clearly seen in the continuous unintended pregnancies and increase of HIV and other STIs prevalence among other outcomes [21] indicating that there is a gap in the response rate to the needs of adolescents in Rwanda. Efforts to attain quality SRH are still constrained by inadequate access to, and inequitable distribution of quality SRH services. In Rwanda, there is still an increase in teen pregnancies, HIV/ STIs as well as reports on the lack of access to accurate SRH information. Although there is a significant increase of the SRH problems in Rwanda, there is a lack of understanding of the perceptions and barriers toward SRH services accessibility, availability and quality, among adolescents in Rwanda. This study was designed to explore the perceptions and barriers toward SRH services accessibility, availability and quality among adolescents in selected cities of Rwanda.

\section{Methods}

\section{Study design}

Cross-sectional study was conducted in six selected cities of Rwanda. In-depth interviews (IDIs) were conducted among adolescents aged 10-19 years to explore their perceptions and barriers toward sexual reproductive health services accessibility, availability and quality in selected cities of Rwanda. In this study, the SRH services including HIV/AIDS and other STIs, pregnancy testing, antenatal and postnatal care, and contraceptive methods were focused during the interview.

\section{Study settings and participants}

A stratified systematic sampling was used to obtain a representative sample in all cities of target while simple random sampling was used to recruit adolescents to take part in the study. Households were the smallest units to find the adolescents to be interviewed in each city of target whereby Villages "known as Imidugudu" were the subarea to be used to allocate a proportional and representative size. A total number of households in each Umudugudu (Village) divided by the sample size of 121 participants provided a sampling interval, and the first house to visit was selected randomly. Every effort was made to include all households selected. If a house was unoccupied at the time of a visit, that house was revisited later that day and if there were no adolescents, we 
visited the next household. If the house was permanently vacant, if the occupants declined to allow the adolescents participate, or if an adolescent was not available for an interview after multiple attempts, then the next closest household was visited. The number of non-respondent households have been recorded on a Household Visitation Log Sheet, to be submitted daily to the research coordinator. Before recruitment, every adolescent was given full information regarding the study aims and design, thus a written assent and consent were signed for adolescents and parents who agreed to participate.

\section{Data collection}

Study pilot was first conducted with 12 participants identified by the investigators through simple random sampling of households within a village in Nyamata city of Rwanda. In-depth interviews were conducted over a period of 6 months from January 2019 to June 2019. 3 co-investigators and 2 recruited/trained data collectors (having knowledge in both quantitative and qualitative research as well as on sexual and reproductive health) facilitated data collection. Each interview lasted between 30 min -1:30 minutes. All the interviews took place in a comfortable area within the community, where every adolescent was free to provide accurate information without pressure. One trained note-taker recorded hand-written notes during each interview to ensure accuracy and check the translation. Data collection was done in a native language, Kinyarwanda. Transcripts from the interviews were translated and analyzed in English by a bilingual researcher for consistency. English translated copies were saved in rich text format and later transferred to ATLAS Ti 5.2 and Statistical Package for Social Sciences (SPSS) for analysis. Ethical approval was obtained from the Institutional Review Board of the University of Rwanda.

\section{Data analysis}

For quantitative, data collected were exported to Statistical Package for Social Sciences (SPSS) software to be analysed from excel. The descriptive analysis was performed based on the frequency and percentage. The crosstabulation and histogrammes were used in the analysis of numerical variables from the participants.

For qualitative analysis, the transcripts from the interviews were translated from Kinyarwanda to English and then analyzed in English by a bilingual researcher for consistency. After translation, English translated copies were saved in rich text format and later transferred to ATLAS Ti 5.2. Analysis of qualitative data was performed for achieving the objectives of the study. To make the results relevant, all transcripts were read by the authors several times and each author provided. Once coding was complete, codes referring to the same topics or sub-themes were grouped into code families and outputs on specific themes were organized and used for report writing. After careful readings and provision of the comments from each author, the discussions among investigators were held to achieve common consensus on the most prevalent perspectives from the participants related to accessibility, availability, quality and barriers to SRH services. Therefore, the following themes were created: (a) awareness of the SRH services provided at health providers; (b) adolescents accessibility to SRH services available; (c) adolescents perceptions on administrative procedure while accessing SRH services; (d) confidentiality and privacy; (e) staff characteristics and youth involvement in the services provided to the adolescents; $(f)$ adolescents involvement; and (g) barriers to SRH services accessibility for adolescents. Thematic analysis was, therefore, achieved and the extracts from each adolescent was taken with common agreement of the researchers.

For data management, data collected was kept in a pass-worded computer that only those involved in the research may get access to. After 2 years, collected data must be deleted from software and others burned with proper supervision from the research team. Quantitative data were extracted into excel sheets then imported to 
SPSS software version 22 for statistical analyses. Regular meetings between authors were conducted to ensure database management and to facilitate discussion/ harmonization of codes as assigned to transcripts.

\section{Results}

\section{Participants Social Demographic Characteristics and Awareness of SRH Services Provided at Health facilities}

A total of 121 adolescents from selected cities were enrolled in this study. The results indicated that the majority (38.8\%) of the study participants were aged 15 to 17 years and females made (62.8\%). Regarding the education level of adolescents, the majority $46(38 \%)$ had primary education level, and ordinary level of secondary school 43(35.5\%) [Table 1].

Among 120 adolescents who responded, 105(86.8\%) participants were aware that sexual and reproductive health $(\mathrm{SRH})$ were provided at health facilities in Rwanda. The results indicated that adolescents aged 18-19 were highly aware of SRH services $41 \%$ compared to other age groups of adolescents. Findings showed that the majority 62 (59\%) of females were more aware of the SRH services provision than males 43 (41\%). Of 105 (86.8\%) adolescents who had awareness of the SRH services provision, majority (36.2\%) of them were found to be studying in ordinary level of secondary school (Table 1).

\section{Adolescents' awareness on the availability of SRH services at health facilities}

There are a variety of SRH services intended to be given at the health facility. We assessed the awareness of participants on availability of the SRH services at nearby health facilities. Most adolescents reported to be aware of SRH services provided at health facilities, whereby the most known available services were circumcision and HIV testing [Table 2]

\section{Utilisation of the sexual reproductive health services}

Among 121 adolescents, only 42 (34.7\%) used some of these services while the remaining 79 (65.3\%) did not use the SRH services. The results indicated that among the services utilised by the adolescents, HIV was mostly used (18.2\%), circumcision (0.83\%), both circumcision and HIV testing (7.4\%), HIV test and HIV testing and antenatal care (ANC) $(0.8 \%)$ [Figure 1].

Qualitative results from in-depth interviews indicated that adolescents faced the barriers to SRH usage such as the limited awareness and poor information or insufficient knowledge about the SRH availability and the health facilities which provided these services. These barriers remain problematic among adolescents in need of them. Adolescents highlighted that they utilized particular SRH service due to their previous awareness of it or during massive community screenings such as during HIV Screening.

"I am aware of my HIV status because I was tested when I was going to receive a transfusion at a hospital" (Female participant, Rwamagana).

Some adolescents responded that seeking SRH services at the health facilities is not possible for them, but they access the SRH services during occasions such as when there are the campaigns organized on particular SRH services, such as HIV testing or VMMC. A 25-year-old male explained:

"We sometimes access the services, once they are testing for HIV during campaigns in our community" 
Many adolescents mentioned their reason for not utilizing SRH to be associated with not being informed. The adolescents indicated that the concern that affects their access to SRH services was lack of real information that resulted to low utilization of the SRH services at youth centers and health facilities:

"We are not aware of the services available for us, no information given to use, and lack of knowledge on why to seek such services prevent some of us from accessing the SRH services"(Female participant, Musanze).

Some adolescents who participated in this study expressed that all of them should utilize these SRH services, especially girls.

"Girls must know those services and be aware of their sexual health as they are the ones who face too much consequences" (Female participant, Kicukiro)

The results indicate that most adolescents from the six selected cities confirmed that the walking distance to the health facilities to access SRH services is less than 30 minutes. However, 6(5.2\%) reported that those services are located too far from them, and that this hinders accessibility because of the long distance it takes to reach the health facilities. Majority of adolescents 104(90.4\%) did not use media channels for getting information regarding $\mathrm{SRH}$ and SRH services provided in the living settings. Accessibility to medical records, and suitability of the daily operating hours were found with $92.3 \%$ for each [Table 3 ].

The qualitative data from the interviewed adolescents are like the quantifiable results. The qualitative data highlighted that socio-cultural and geographical constraints were the barriers which negatively affected their accessibility to SRH services. It was, therefore, found that misinformation and poor information related to the service delivery was the barrier:

"I do not use social media for getting information regarding SRH services. We get false information from colleagues, and it is sometimes difficult to be informed of the places where we can find reliable information on SRH services accessibility" (Male participant; Gasabo).

Adolescents' experiences suggest that health care providers rendering SRH services to them were willing to avail their medical history to adolescents whereby $24(92.3 \%)$ accessed them freely, and $23(76.67 \%)$ did not miss any service they needed:

"Yes; sometimes when I request more information on my SRH medical history, it is provided easily". (Male participant, Rwamagana).

It was also revealed that some $\mathrm{SRH}$ resources are not available at the health facilities. Some interviewed adolescents admitted that condoms are available for males, while female condoms are not available in health facilities.

"No; male condoms are easily accessible and available but female condoms are not there (Female participant, Musanze)"

\section{Adolescents perceptions on administrative procedure while accessing SRH services}

The results indicated that $96.2 \%$ of the services are provided free of charge and $92.3 \%$ of adolescents reported that the services are delivered at a suitable period of the time, however, the majority (66.6\%) reported lack of staff 
members to oversee ASRH services. Adolescents showed that they spend little time waiting for the services. However, 3.9\% stated that they wait for over one hour to be given the SRH service at the health facility [Table 3]. While it is likely that utilising health insurance addresses the problems related to high service cost when seeking SRH services, some adolescents mentioned that in private health facilities, the cost of SRH services is not favorable for them.

"The cost of circumcision is high within the private health facilities, I paid more than 10,000 Rwandan francs"(Male participant, Gasabo).

\section{Confidentiality and privacy}

The results demonstrate that close to half of the health facilities still provide SRH services in the same room for both Adolescents and adults. About 12(46.2\%) of adolescents who at least used the SRH services stated that the health facilities in charge of providing the services had not comfortable rooms or separated rooms for delivering the SRH services to the adolescents. The adolescents thought about what adults would think of them once they saw them looking for SRH services. 29(92.6\%) of participants who used the services accepted that they are not asked for guardian permission [Table 4].

"We are able to utilize or access the SRH services at health facilities without parent/guardian consent because everyone enters alone in the rooms of service providers" (Female participant, Gasabo).

The interviewed adolescents also reported the difficulties of having a desired waiting space while waiting for access to the SRH services delivery $(14.8 \%)$. Moreover, some adolescents had witnessed that some facilities have comfortable waiting spaces at the SRH services department (85.2\%). Adolescents' friendly services were said to be more accessible in youth friendly centers and are the main one that were reported to provide educational materials to adolescents.

"At Dushishoze [a youth friendly health center], they provide books and articles on SRH information and services such that you can even carry them at home."(Male participant, Huye).

\section{Staff characteristics and youth involvement in the services provided to the adolescents}

The findings showed that all the adolescents that the staff of the health facilities that offer SRH services among the adolescents were knowledgeable that the SRH services were friendly provided (74.1\%), but only close to half of adolescents indicated that $62.07 \%$ of the health providers spent the extra-time to provide the adequate services to the adolescents. It was found that only $50 \%$ of health providers delivered to the adolescents general information on health during SRH services provision Majority $(74.1 \%)$ of the interviewed adolescents revealed that the staff of the health facility provided the SRH services to them with no judgment but friendly and appreciable welcoming, however, $25.9 \%$ of the adolescents reported that the health providers did not provide the SRH services friendly and adequately to the adolescents. Findings indicated that a half of health providers provide essential information on health and $92.6 \%$ of health providers provided to the adolescents SRH services with respect [Table 5].

The results demonstrated that the involvement of the adolescents in the SRH services they need remains low. To involve peer educators in the services was low (18.5\%), and involvement of adolescents in designing the feedback mechanism was $19.2 \%$ while availability of transparent and confidential mechanism for complaints about SRH 
services was 48\% [5]. Qualitative data confirmed that health services providers provide effective SRH services to adolescents.

"Sometimes when making conversations with SRH services providers, you realize that they are knowledgeable" (Male participant, Rubavu).

"Looking into the way a service provider informs and responds to my questions, shows me that she is knowledgeable" (Female adolescent, Rwamagana).

The staff professional attitude was described by the respondents and the majority of the adolescents' said that providers gave them more information on the $\mathrm{SRH}$ services they have offered to them:

"Before and after circumcision they teach the importance of circumcision and that it does not prevent HIV at $100 \%$ " (Male participant, Huye).

\section{Adolescents involvement}

The study explored the involvement of adolescents with SRH provision to their peers and in the overall provision of services, and young people are not available at 22(81.5\%) as peer educators or counsellors at urban health facilities where adolescents attend for SRH services.

“There are only older people who provide us SRH services (Male participant, Rwamagana)

"I have seen that the majority of those who provide SRH services and information are possibly over than 30 years old "(Male participant, Gasabo)

The results from the adolescents indicated that 21(80.77\%) respondents reported the absence of adolescents' involvement in designing feedback mechanisms and 13(52\%) respondents pointed out the lack of transparent mechanisms to give complaints or demonstrate dissatisfaction [5]. The qualitative results presented that the adolescents are not involved in that they should be provided and availability of various opportunities that help them to access SRH services remained the concern. They also indicated that they lack the opportunities that should help them to increase SRH awareness, positive perceptions, and effective utilization of the resources:

"We do not receive an open opportunity to give and provide ideas on the sort of services they should give us [adolescents]" (Female participant, Huye).

The study has also shown that some adolescents did not have any information on the age at which they are allowed to access these SRH services or if they are actually supposed to use those services. Majority of the adolescents who were participants in this study believe that only adults are supposed to use the SRH services or at least a menstruating adolescent can be allowed to access the SRH services.

"I think to be allowed to access the SRH services, adolescents should be 15 years old because she knows what he or she is doing at that age" (Male participant, Rubavu).

"We can be allowed to access and utilize the SRH services at 12years old because most of at that age, adolescents start menstruation." (Female participant, Kigali). 


\section{Barriers to SRH services accessibility for adolescents}

Interviewed adolescents also mentioned various barriers such as: lack of information about comprehensive SRH services for adolescents and where they can be accessed, community-stigma surrounding accessibility to SRH services, unaffordable services within private health facilities, fearing parents and church leaders on what they might think about adolescents who try to utilize or request SRH services and judgmental attitudes of some health service providers.

Our findings communicate that there are people influencing adolescents' poor utilisation of SRH services. Adolescents were asked about their experienced perceptions about community members, family members, friends, religious leaders, among others on their influence toward utilizing or not utilizing the SRH services for adolescents. Our results demonstrate that the family members occupied the highest position of people 53 (44.9\%) who limit access to SRH services for adolescents, followed by community members $36(30.5 \%)$ and religious leaders 34 (28.8\%) coming third on the list of people who limit access or utilization of SRH services for adolescents in urban settings of Rwanda. This might affect the accessibility to SRH services because adolescents were afraid, had self and social stigma from community in looking for the SRH services:

“Community members limit adolescents' access to SRH services because they may gossip about you, we also fear them, and being ashamed if they saw me accessing those services, and therefore, I do not want them to know that I utilize SRH services" (Female participant, Kicukiro).

Adolescents indicated that the health care providers have a positive attitude of SRH that help them to provide for the adolescents with confidentiality and respect the SRH services. An adolescent said:

"Health care provider for us in confidential manner and privacy because everyone gets results alone"

The adolescents highlighted that the inaccessibility to SRH services was due to lack of privacy, confidentiality and equipment of health facilities. These attitudes caused them not to go seeking health care services at the health facilities nor discuss their SRH problems. A participant said:

"The services like circumcision is done during military week where more than one adolescent enters the room." Another expressed.

In addition to that, the results indicated that the negative attitudes of the family members challenged them to access the SRH services. For instance; the family relatives and parents limited adolescents, spreading wrong and/or confidential information related to the services provided:

"Community members such as neighbors may spread the information to others while I did this in a private way to limit people who knows what I do in relation to sex issues and SRH in general". (Female participant, Kigali)

"Family members often limit us to access SRH services because this is linked to being a bad child or to having bad manners if it is known that you want or access SRH services". ～(Male participant, Huye)

"Family members limit us to access SRH services. I cannot try to access or request such a service if there someone who knows me around because they will spread rumors in my family that I am pregnant or that I am a prostitute" said a female adolescent from Kigali. 
The qualitative findings indicated that socio-cultural norms constitute the important barrier to access SRH services where the religious leaders limit the adolescents for using SRH services. The findings demonstrated that the religious beliefs were an important contributing factor to the low access to SRH services:

"Religious leaders are the principal people who limit me to access the SRH services because they are refusing service utilization in general" (Male participant, Rubavu).

Another participant explained:

"Religious leaders prevent me to access and utilize SRH services because they will send me outside of the church and therefore, I do not even try to buy a condom from a nearby shop to prevent people from telling our pastors and other church leaders" (Female participant, Rubavu).

\section{Discussion}

Prior studies indicated that reproductive health needs of adolescents were discovered to be largely ignored by existing health, education, and other social programs $[6,21]$. The Rwandan health system has made efforts to increase the accessibility to SRH services among young people through establishing a Youth corner at every health center. However, despite these efforts, the results of the current study revealed that the usage of SRH services among adolescents remains low (34.7\%) in the selected cities. It was mentioned HIV testing was mostly used. These results are similar to the findings the research conducted in other low- and middle-income countries which showed the adolescents' access to SRH remains low $[17,18]$.

The results revealed that the awareness of SRH services was $86.4 \%$. Adolescents confirmed that among the services in which they were lowly aware of, the males, illiterate adolescents and adolescents who studied primary schools, and adolescents aged 17-19 year were mentioned. These findings were supported by the previous studies that reported that the poorly educated adolescents and boys were poorly aware and had access to the SRH services [9]. Few of them seek HIV testing willingly and by personal decision. This complement was found in the study done in Rwanda showing that young people have partial and often inaccurate knowledge about SRH and have difficulty in accessing health services. They tend to rely on the radio and their peers for information [19]. The need to increase awareness of SRH services may be one of important interventions that has to be implemented in order to promote adolescent's well being. Some adolescents suggest this to be done through school clubs and youth meetings [4].

Although poor accessibility remains a national burden among adolescents, high prevalence of early pregnancies, HIV and STIs, low access to Voluntary Male Medical Circumcision (VMMC) remain the SRH concerns in both rural and urban areas $[19,23]$. Thus, there was a need to seek reasons responsible for the low uptake of services being offered to adolescents aged 10-19 years in Rwanda cities as the cities have a great number of adolescents.

Presence of SRH services to be friendly used by adolescents is essential for promoting sexual reproductive health but supply of equipment required for enabling the provision of these services is another vital requirement which enables providers to deliver quality services. Through the results, this was among the barriers that was revealed within this study; whereby some health services such as female condoms were unavailable at the health facilities, facilities lack privacy, poor information or insufficient knowledge about the SRH availability and confidentiality. 
However, the national guideline for ASRH further demands that service delivery points should be organized in a manner that is conducive for provision of adolescents friendly reproductive health services. The results of the current study revealed that the adolescents faced the barriers to access the SRH services. The barriers to SRH services amongst adolescents included high cost for SRH services at the private health facilities to avail and provide the SRH services, socio-cultural barriers characterized by the parents and religious beliefs that influence the adolescents to not utilize the SRH services, having fear and shame to use these services, poor parental supervision and unsafe rooms for delivering the $\mathrm{SRH}$ services to adolescents did not respect confidentiality and privacy. The findings are supported by the previous studies $[13,16,18]$.

Like the outcome from other studies, social and cultural norms, stigma from the community are the major concerns that limit adolescents who know about YFCs to use the services $[19,21]$. In our country, based on the religious norms and our culture, it could not be easy for anyone to access those services as he/she could be taken as sex worker and adolescent with no manners and some of us consider it as a sin. Community support is needed, to train parents and religious leaders to change their mind and perception towards adolescents who use those services and increase adolescent-guardians discussion to get common understanding about SRH service use. Stigma towards adolescents must be eradicated as many reported family members and religious leaders as people they did not ever wish to meet at YFC because they cannot find explanations to what they are doing there. These results are supported by the previous studies that most health facilities lacking privacy, not having the staff of the same sex, having health providers who had negative attitudes and behaviors, stigma and discrimination, health providers lacking confidentiality in the provision of SRH services [17].

As other studies conducted, adolescents in our study pointed to lack of confidentiality as one of the challenges leading to low utilization of SRH services. Health care providers are among key features that can affect the utilization of the services even though the services may be known and available. Many adolescents fear to come to the YFC as sometimes the healthcare providers were not able to keep confidentiality about the SRH information about the adolescents and go around gossiping everywhere in the region about one' SRH status [18]. Also sharing the same room with adults bleaches the will of adolescents as old people may take them in another bad image depending on their perceptions. These results are supported by the evidence from the previous studies that indicated the social stigma, fear, self-stigma, fear of loss of cultural identity were the barriers to SRH usage [18, 24].

In addition, financial means also has to be given priority in the changes that has to be made as it has been proven that in some centers the services are not being provided freely and not all of them could afford their cost as it is shown in $[25,26]$. Also, YFCs must be established nearly to all health centers so that adolescents don't need to walk too far or pay much transportation fees and work in convenient hours so that all may be able to access anytime SRH services are needed. These results are supported by the previous studies that indicated that the lack of environment and financial constraints are the barriers to the utilization of SRH services that should be provided to the adolescents [13].

The study was limited to conduct current in all adolescents from all the districts of the countries such as the cities which are not from the districts not nationally targeted to be the second cities. Meanwhile, the adolescents from the rural settings were not involved in the current study, however, in each large city we administered the study among the adolescents from both rural and urban areas. Basing on the study limitations found, it is the responsibility of everyone to strengthen the wellbeing of our community by protecting adolescents as future generations and the country' economy by preventing STIs and early pregnancy accompanied by leaving the 
schools, rejection from the community, increase of street children and other impacts that weakens the sustainable development of our country.

\section{Conclusion}

Adolescents from Rwandan main cities showed that they face some barriers that limit them from accessing SRHs as some of them do not even know where they could find those services in case they are needed. To second the results from this study, all corners engaged including guardians, community leaders, SRHs providers are the ones to take the first step in eradicating these barriers and promote adolescent wellbeing and avoid stigma from the community that most adolescents fear. Awareness of YFCs, their undertaken activities and operating hours must be spread to all adolescents through school clubs and communities where adolescents meet.

The future research should:(1) design, implementation and evaluation operational interventions addressing the socio-cultural and economic drivers of SRH services for reducing socio-cultural barriers to SRH services among adolescents; (2) Carry out the study for understanding perceptions and barriers toward sexual reproductive health services accessibility, availability and quality among adolescents in Rwanda and then compare the results to findings from the second cities and Kigali city. ; and (3) Epidemiological study to explore the factors associated with the availability, accessibility and quality of SRH services among Rwandan adolescents.

\section{Abbreviations}

ICPD

International Conference on Population and Development

AIDS

Acquired Immuno-Deficiency Syndrome

CMHS

College of Medicine and Health Sciences

HIV

Human Immuno-deficiency Virus

SPSS

Statistical Package for Social Sciences

$\mathrm{SRH}$

Sexual and Reproductive Health

STI

Sexual Transmissible Infections

WHO

World Health Organization

YFC

Youth Friendly Center

YSO

Youth Services Organization

\section{Declarations}




\section{Ethics approval and consent to participate}

The study received ethical clearance (Ref: CMHS/IRB/372/2018) from the University of Rwanda, College of Medicine and Health Sciences Institutional Review Board. Districts authorities provided permissions to conduct data collection in their districts. Participants were informed about the aim of the study and gave written assent and/or consent before participating in the study. Written informed consents were obtained from the parents or guardians and the recruited adolescents provided assent. Confidentiality and privacy were maintained by ensuring that IDIs were performed in the private and comfortable spaces for the participants. Numeric identification codes were used to conceal individual identities and the author securely handled all records. Anonymity and confidentiality for identifying the names, and location were maintained. Subjects were able to participate in choosing the appropriate area for conducting the interview.

\section{Competing interests}

The authors declare no competing interests.

\section{Consent for publication}

All the others gave verbal consent to publish this paper.

\section{Availability of data and materials}

All data and materials used in this study are available from the corresponding author on request.

\section{Funding}

The authors are grateful for the generous funding from ViiV Healthcare through Positive Action for adolescents' program.

\section{Authors' Contributions}

PN, AD and DRK participated in conceptualizing, study design, data collection, data analysis and manuscript writing. IK and EB participated in data collection, analysis and interpretation. JBN participated in revising the manuscript. All authors participated in drafting and revising the manuscript. They also read and approved the final version of the manuscript.

\section{Acknowledgments}

We also thank the adolescents who participated in the study, local leaders and we also acknowledge the scientific and mentorship received from our mentors, especially Professor Justin Kadima Ntokamunda and Dr. Stefan Jansen.

\section{References}

1. Coast E, Jones N, Francoise UM, Yadete W, Isimbi R, Gezahegne K, et al. Adolescent Sexual and Reproductive Health in Ethiopia and Rwanda: A Qualitative Exploration of the Role of Social Norms. Reprod Heal SubSaharan Africa-Original Res. 2019;9(1):1-16. Available from: https://doi.org/10.1177/2158244019833587 
2. Aninanya GA, Debpuur CY, Awine T, Williams JE, Hodgson A, Howard N. Effects of an adolescent sexual and reproductive health intervention on health service usage by young people in northern Ghana: A communityrandomised trial. PLoS One. 2015;10(4):1-16. Available from: https://doi.org/10.1371/journal.pone.0125267

3. Chandra-mouli V, Svanemyr J, Amin A, Fogstad H, Say L, Girard F, et al. Twenty Years After International Conference on Population and Development: Where Are We With Adolescent Sexual and Reproductive Health and Rights? J Adolesc Heal. Elsevier Inc.; 2015;56(1):S1-6. Available from:

https://doi.org/10.1016/j.jadohealth.2014.09.015

4. Godia PM, Olenja JM, Hofman JJ, Broek N Van Den. Young people's perception of sexual and reproductive health services in Kenya. BMC Health Serv Res. 2014;14:1-13. Available from: https://doi.org/10.1186/14726963-14-172

5. Ringheim K, Gribble J. Improving the Reproductive Health of sub-Saharan African Youths: A route to achieve the Millenium Development Goals [Internet]. Washington, USA; 2010. Available from:

https://www.prb.org/youthchartbook/

6. United Nations. International Conference on Population and Development Programme of Action. 20th Anniv. United Nations Population Fund (UNFPA);2014. pp.5-13. Available from: https://www.unfpa.org/publications/international-conference-population-and-development-programmeaction

7. UN Children's Fund. National Consultant National Operational Plan for adolescents. Kigali, Rwanda; 2016. Available from: http://www.myunjobs.com/job/135195-Rwanda:-National-Consultant---National-OperationalPlan-for-adolescents-in-Rwanda

8. Ministry of Health. National Family Planning and Adolescent Sexual and Reproductive Health (FP/ASRH) Strategic Plan. Kigali, Rwanda; 2018. Available from:

http://www.moh.gov.rw/fileadmin/Publications/Strategic_Plan/Rwanda_Adolescent_Strategic_Plan_Final.pdf

9. Agampodi SB, Agampodi TC, Ukd P. Adolescents perception of reproductive health care services in Sri Lanka. BMC Health Serv Res. 2008;8:1-8. Available from: https://doi.org/10.1186/1472-6963-8-98

10. Ministry of Health and Social Welfare. The National Road Map Strategic Plan To Accelerate Reduction of Maternal, Newborn and Child Deaths in Tanzania. Tanzania; 2008. Available from:

https://www.who.int/pmnch/countries/tanzaniamapstrategic.pdf

11. Denno DM, H MP, Hoopes AJ, D M, Chandra-mouli V, Sc M. Effective Strategies to Provide Adolescent Sexual and Reproductive Health Services and to Increase Demand and Community Support. J Adolesc Heal. Elsevier Inc.; 2015;56(1):S22-41. Available from: https://doi.org/10.1016/j.jadohealth.2014.09.012

12. Godia PM, Olenja JM, Lavussa JA, Quinney D, Hofman JJ, Broek N Van Den. Sexual reproductive health service provision to young people in Kenya; health service providers' experiences. BMC Health Serv Res. 2013;13:476. Available from: https://doi.org/10.1186/1472-6963-13-476

13. Iqbal S, Zakar R, Zakar MZ, Fischer F. Perceptions of adolescents' sexual and reproductive health and rights: a cross- sectional study in Lahore District, Pakistan. Int Heal Hum Rights [Internet]. BMC International Health and Human Rights; 2017;17(5):1-13. Available from: https://doi.org/10.1186/s12914-017-0113-7

14. International Planned Parenthood Federation. Keys to youth-friendly services: Introducing the series. London; 2012. Available from: https://www.ippf.org/sites/default/files/keys_introduction.pdf

15. Mulaudzi M, Dlamini BN, Coetzee J, Sikkema K, Gray G, Dietrich JJ. Perceptions of counsellors and youthserving professionals about sexual and reproductive health services for adolescents in Soweto, South Africa.

Page $15 / 23$ 
Reprod Health. Reproductive Health; 2018;15(1):15: 21. Available from: https://doi.org/10.1186/s12978-0180455-1

16. Geary RS, Kahn K, Norris SA. Barriers to and facilitators of the provision of a youth-friendly health services programme in rural South Africa. BMC Health Serv Res. 2014;14(June):1-8. Available from: https://doi.org/10.1186/1472-6963-14-259

17. Mbeba RM, Mkuye MS, Magembe GE, Yotham WL, Mellah A, Baptist S. Barriers to sexual reproductive health services and rights among young people in Mtwara district, Tanzania: a qualitative study. Pan Afr Med J. 2012;13(Supp 1):1-6. PMID: 23467684; PMCID: PMC3589247.

18. Kaufman MR, Smelyanskaya M, Lith LM Van, Mallalieu C, Waxman A, Hatzhold K, et al. Adolescent Sexual and Reproductive Health Services and Implications for the Provision of Voluntary Medical Male Circumcision: Results of a Systematic Literature Review. PlosOne. 2016;11(3):e0149892. Available from: https://doi.org/10.1371/journal.pone.0149892

19. Abbott P, Rwirahira J, Mugisha R, Mutesi L, Tuyishime C, Vuningoma L. Lifestyle and Sexual and Reproductive Health in Rwanda: Findings from a Purposive Qualitative Study. Population Media Centre-Rwanda; 2014. Available from: https://doi.org/10.13140/2.1.2284.8643

20. UNFPA ESARO. Assessment of Adolescent and Youth-Friendly Health Service Delivery in the East and Southern Africa Region [Internet]. Sunninghill, South Africa; 2017. Available from:

https://esaro.unfpa.org/en/publications/assessment-adolescent-and-youth-friendly-health-service-deliveryeast-and-southern

21. UN, UNICEF, RBC. Phase 1 "All in" Rapid Assessment Report: Adolescent HIV Program Context Analysis 2015. Kigali, Rwanda; 2017. Available from: https://www.unicef.org/events_20676.html

22. Boerboom L, Gibert M, Spaliviero M, Spaliviero G. The Spatial Development Framework for Implementation of National Urban Policy. In: In Proceedings of GeoTech Rwanda 2015. Kigali, Rwanda; 2015. p. 1-9.

23. HDI. Expanding Adolescents and Youth Access to Sexual and Reproductive Health Services in Rwanda: Policy brief. Kigali; 2018. Available from: http://hdirwanda.org/wp-content/uploads/2019/04/Policy-brief-

Expanding-Adolescents-and-Youth-access-to-SRH-services-in-Rwanda.pdf

24. Mutuku B, Boerboom L, Madureira AM. The role of Planning Support Systems in national policy transfer and policy translation in secondary cities. Int Plan Stud. Taylor \& Francis; 2019;24(3-4):293-307. Available from: https://doi.org/10.1080/13563475.2019.1657809

25. Obong'o C, Zani A. Evaluation of the Provision of Sexual and Reproductive Health Services to Young People in Wagai and Karemo Divisions, Siaya. IOSR J Humanit Soc Sci. 2014;19(8):89-99. Available from:

www.iosrjournals.org

26. Odo AN, Samuel ES, Nwagu EN, Nnamani PO, Atama CS. Sexual and reproductive health services (SRHS) for adolescents in Enugu state, Nigeria: a mixed methods approach. BMC Health Serv Res. BMC Health Services Research; 2018;92:1-12. Available from: https://doi.org/10.1186/s12913-017-2779-x

\section{Tables}

Table 1: Characteristics of the participants and awareness of the SRH services provided at health providers 


\begin{tabular}{|c|c|c|c|c|c|c|}
\hline \multirow[t]{2}{*}{ Socio-demographic } & \multicolumn{2}{|c|}{ Awareness $(\mathrm{N}=105)$} & \multicolumn{2}{|c|}{ Unaware $(\mathrm{N}=16)$} & \multirow[b]{2}{*}{ Total } & \multirow[b]{2}{*}{ Percent } \\
\hline & Number & Percent & Number & Percent & & \\
\hline \multicolumn{7}{|l|}{ Age of participants } \\
\hline $10-14$ & 22 & 21.0 & 7 & 43.8 & 29 & 24.0 \\
\hline $15-17$ & 40 & 38.1 & 7 & 43.8 & 47 & 38.8 \\
\hline $18-19$ & 43 & 41.0 & 2 & 12.5 & 45 & 37.2 \\
\hline \multicolumn{7}{|l|}{ Gender } \\
\hline Male & 43 & 41.0 & 2 & 12.5 & 45 & 37.2 \\
\hline Female & 62 & 59.0 & 14 & 87.5 & 76 & 62.8 \\
\hline \multicolumn{7}{|l|}{ Education } \\
\hline Illiterate & 3 & 2.9 & 0 & 0.0 & 3 & 2.5 \\
\hline Primary schools & 36 & 34.3 & 10 & 62.5 & 46 & 38.0 \\
\hline Secondary - O’L & 38 & 36.2 & 5 & 31.3 & 43 & 35.5 \\
\hline Secondary - A'L & 25 & 23.8 & 1 & 6.3 & 26 & 21.5 \\
\hline University & 3 & 2.9 & 0 & 0.0 & 3 & 2.5 \\
\hline
\end{tabular}

Table 2: Adolescents awareness on SRH services availability 


\begin{tabular}{|c|c|c|c|c|}
\hline \multirow[t]{2}{*}{ Sexual Reproductive Health services } & \multicolumn{2}{|c|}{ Aware } & \multicolumn{2}{|c|}{ Not aware } \\
\hline & $\mathbf{N}$ & $\%$ & $\mathbf{N}$ & $\%$ \\
\hline \multicolumn{5}{|l|}{ Health services for HIV and other STIs } \\
\hline HIV testing & 102 & 86.4 & 16 & 15.6 \\
\hline STI testing & 101 & 85.6 & 17 & 14.4 \\
\hline HIV self-testing kits & 99 & 83.9 & 19 & 16.1 \\
\hline STI management & 101 & 85.6 & 17 & 14.4 \\
\hline HIV counselling & 101 & 85.6 & 17 & 14.4 \\
\hline \multicolumn{5}{|l|}{ Services related to pregnancies } \\
\hline Contraceptives & 99 & 83.9 & 18 & 15.4 \\
\hline Pregnancy tests & 98 & 84.5 & 18 & 15.4 \\
\hline \multicolumn{5}{|l|}{ Services for family planning } \\
\hline IUD for 5-10 years & 99 & 83.9 & 18 & 15.4 \\
\hline Implants & 100 & 85.5 & 17 & 14.5 \\
\hline Pills & 100 & 85.5 & 17 & 14.5 \\
\hline Depo-Provera Injection & 100 & 85.5 & 17 & 14.5 \\
\hline Male condoms & 100 & 85.5 & 18 & 15.4 \\
\hline Female condoms & 100 & 85.5 & 17 & 14.5 \\
\hline Emergency contraceptives & 100 & 85.5 & 19 & 16.2 \\
\hline Fertility awareness & 100 & 85.6 & 17 & 14.5 \\
\hline \multicolumn{5}{|c|}{ Services for pregnant woman during or post-natal period } \\
\hline Vasectomy & 98 & 84.5 & 18 & 15.4 \\
\hline Tubal ligation & 98 & 83.8 & 19 & 16.2 \\
\hline Antenatal care & 99 & 85.3 & 17 & 14.5 \\
\hline Postnatal care & 98 & 84.5 & 17 & 14.5 \\
\hline Circumcision & 102 & 86.4 & 16 & 13.6 \\
\hline
\end{tabular}

Table 3: Main features that affect SRH services utilization 


\begin{tabular}{lll}
\hline Variables & Number & Percent \\
\hline
\end{tabular}

Walking distance from home to health facility

$\begin{array}{lcc}\leq 30 \text { min } & 71 & 61.2 \\ 30-60 \text { min } & 33 & 28.4 \\ >60 \text { min } & 6 & 5.2 \\ \text { Don't Know } & 6 & 5.2\end{array}$

Social media use to get health information

$\begin{array}{lcc}\text { Yes } & 11 & 9.6 \\ \text { No } & 104 & 90.4\end{array}$

Access to medical records

$\begin{array}{lcc}\text { Yes } & 24 & 92.3 \\ \text { No } & 2 & 7.7\end{array}$

Any needed SRH service that is missing at health facility

$\begin{array}{lll}\text { Yes } & 7 & 23.3 \\ \text { No } & 23 & 76.7\end{array}$

Waiting time for service

$\begin{array}{lcc}\leq 30 \mathrm{~min} & 21 & 80.7 \\ 31-60 \mathrm{~min} & 4 & 15.4 \\ >60 \mathrm{~min} & 1 & 3.9\end{array}$

Cost for the services

$\begin{array}{lll}\text { Free } & 18 & 69.2\end{array}$

$\begin{array}{lll}\text { Low cost } & 5 & 19.2\end{array}$

$\begin{array}{lll}\text { High cost } & 3 & 11.6\end{array}$

Suitability of operating hours per day

$\begin{array}{lcc}\text { Yes } & 24 & 92.3 \\ \text { No } & 2 & 7.7\end{array}$

Frequency of the information about adolescents' friendly services
Always
10
8.7
Sometimes
57
49.6
Never
48
41.7

Provision of time to understand the laboratory results
Yes
26
96.3
No
1
3.7

Having a staff member to oversee AFSRH services

\begin{tabular}{lcc} 
Yes & 7 & 33.3 \\
No & 14 & 66.6 \\
\hline
\end{tabular}

Page 19/23 
Table 4: Confidentiality, privacy and service delivery environment for the SRH

\begin{tabular}{lcc}
\hline Characteristics & Number & Percent \\
\hline Separate service rooms from adults & & \\
Yes & 14 & 53.8 \\
No & 12 & 46.2
\end{tabular}

Service providers ensure privacy \& confidentiality

$\begin{array}{lcc}\text { Yes } & 26 & 96.3 \\ \text { No } & 1 & 3.7\end{array}$

Utilisation of service without guardian' consent

$\begin{array}{lll}\text { Yes } & 78 & 73.6 \\ \text { No } & 28 & 26.4\end{array}$

SRH education materials available

$\begin{array}{lll}\text { Yes } & 20 & 74.1 \\ \text { No } & 7 & 25.9\end{array}$

Service has adequate and comfortable waiting area

\begin{tabular}{lll} 
Yes & 23 & 85.2 \\
No & 4 & 14.8 \\
\hline
\end{tabular}

Table 5: Staff characteristics and youth involvement 


\begin{tabular}{|c|c|c|}
\hline Staff characteristics & Number & Percent \\
\hline A. Staff characteristics & & \\
\hline \multicolumn{3}{|c|}{ Knowledgeable staff on SRHs } \\
\hline Yes & 27 & 100 \\
\hline No & 0 & 0 \\
\hline \multicolumn{3}{|c|}{ Non-judgmental, friendly and welcoming staff } \\
\hline Yes & 20 & 74.1 \\
\hline No & 7 & 24.9 \\
\hline \multicolumn{3}{|l|}{ Staff demonstrating respect } \\
\hline Yes & 25 & 92.6 \\
\hline No & 2 & 7.4 \\
\hline \multicolumn{3}{|c|}{ Staff with access to reference materials } \\
\hline Yes & 19 & 90.5 \\
\hline No & 2 & 9.5 \\
\hline
\end{tabular}

Staff provide extra-time for individual adolescents once needed

\begin{tabular}{lcc} 
Yes & 18 & 62.07 \\
No & 11 & 37.93 \\
\hline Staff provide further information on SRH service rendered & & 46.9 \\
\hline Yes & 23 & 14.3 \\
No & 7 & 38.8 \\
Don't know & 19 & \\
\hline Staff provide general information on Health & 13 & 50 \\
\hline Yes & 13 & 50 \\
\hline No & 13 \\
\hline
\end{tabular}

B. Youths involvement

Availability of peer educators/counselors

$\begin{array}{lcc}\text { Yes } & 5 & 18.5 \\ \text { No } & 22 & 81.5\end{array}$

Availability of transparent and confidential mechanism for complaints about SRHs
Yes
$12 \quad 48$
No
$13 \quad 52$

Adolescents involvement in designing feedback mechanism

$\begin{array}{lcc}\text { Yes } & 5 & 19.2 \\ \text { No } & 21 & 80.8\end{array}$


Table 6: Barriers to utilization of SRH services among adolescents

\begin{tabular}{lcc}
\hline People who can limit adolescents' access to SRHs & Number & Percent \\
Community member & 36 & 30.5 \\
\hline Family member & 53 & 44.9 \\
\hline Friends & 19 & 16.1 \\
\hline SRH service staff & 14 & 11.8 \\
\hline Adolescents & 18 & 15.4 \\
\hline Policy makers & 18 & 15.4 \\
\hline Religious leaders & 34 & 28.8 \\
\hline None & 32 & 27.1 \\
\hline
\end{tabular}

Figures 


\section{SRH services used by adolescents}

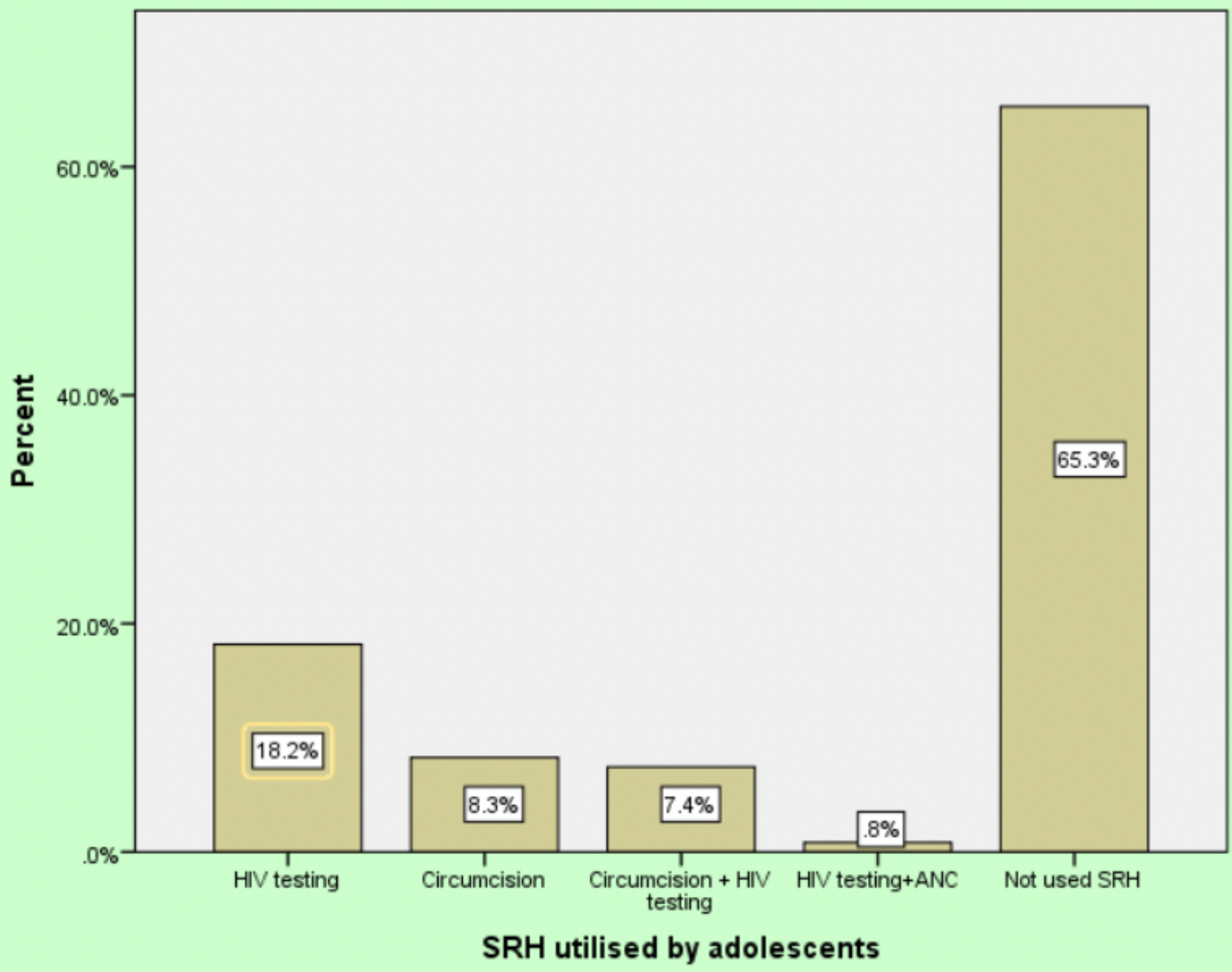

Figure 1

SRH services utilisation for the adolescents 